\title{
Mucopolysaccharidosis type II (Hunter syndrome): a clinical review and recommendations for treatment in the era of enzyme replacement therapy
}

\author{
J. Edmond Wraith • Maurizio Scarpa • Michael Beck • \\ Olaf A. Bodamer • Linda De Meirleir • \\ Nathalie Guffon • Allan Meldgaard Lund • \\ Gunilla Malm • Ans T. Van der Ploeg • Jiri Zeman
}

Received: 22 June 2007 / Revised: 29 October 2007 / Accepted: 29 October 2007 / Published online: 23 November 2007

(C) The Author(s) 2007

\begin{abstract}
Mucopolysaccharidosis type II (MPS II; Hunter syndrome) is a rare $\mathrm{X}$-linked recessive disease caused by deficiency of the lysosomal enzyme iduronate-2-sulphatase, leading to progressive accumulation of glycosaminoglycans in nearly all cell types, tissues and organs. Clinical manifestations include severe airway obstruction, skeletal deformities, cardiomyopathy and, in most patients, neurological decline. Death usually occurs in the second decade of life, although some patients with less severe disease have survived into their fifth or sixth decade. Until recently, there has been no effective therapy for MPS II, and care has been palliative. Enzyme replacement therapy (ERT) with recombinant human iduronate-2-sulphatase (idursulfase), however, has now been introduced. Weekly intravenous infusions of idursulfase have been shown to improve many of the signs and symptoms and overall wellbeing in patients with MPS II. This paper provides an overview of the clinical manifestations, diagnosis and symptomatic management of patients with MPS II and provides recommendations for the use of ERT. The issue of
\end{abstract}

J. E. Wraith $(\bowtie)$

Willink Biochemical Genetics Unit,

Royal Manchester Children's Hospital, Hospital Road,

Manchester M27 4HA, UK

e-mail: ed.wraith@cmmc.nhs.uk

M. Scarpa

Centre for Rare Diseases, University of Padua,

Padua, Italy

M. Beck

Universitäts Kinderklinik,

Mainz, Germany

O. A. Bodamer

Universitäts Klinik für Kinder- und Jugendheilkunde,

Vienna, Austria treating very young patients and those with CNS involvement is also discussed. ERT with idursulfase has the potential to benefit many patients with MPS II, especially if started early in the course of the disease.

Keywords Mucopolysaccharidosis type II .

Hunter syndrome - Enzyme replacement therapy ·

Idursulfase $\cdot$ Treatment recommendations

$\begin{array}{ll}\text { Abbreviations } \\ \text { CNS } & \text { Central nervous system } \\ \text { ERT } & \text { Enzyme replacement therapy } \\ \text { GAGs } & \text { Glycosaminoglycans } \\ \text { HOS } & \text { Hunter Outcome Survey } \\ \text { HSCT } & \text { Haematopoietic stem cell transplantation } \\ \text { I2S } & \text { Iduronate-2-sulphatase } \\ \text { M6P } & \text { Mannose-6-phosphate } \\ \text { MPS } & \text { Mucopolysaccharidosis }\end{array}$

L. De Meirleir

University Hospital VUB, Brussels, Belgium

N. Guffon

Edouard Herriott Hospital, Lyon, France

A. Meldgaard Lund

Rigshospitalet, Copenhagen, Denmark

G. Malm

Karolinska Hospital, Huddinge, Sweden

A. T. Van der Ploeg

Erasmus Medical Centre, Rotterdam, The Netherlands

J. Zeman

Charles University, Prague, Czech Republic 


\section{Introduction}

First described by Major Charles Hunter in 1917 [15], mucopolysaccharidosis type II (MPS II or Hunter syndrome; OMIM +309900) is an X-linked recessive disease caused by deficiency of the lysosomal enzyme iduronate-2-sulphatase (I2S). This enzyme cleaves O-linked sulphate moieties from the glycosaminoglycans (GAGs) dermatan sulphate and heparan sulphate as the first step in their degradative pathway. The clinical phenotype of MPS II (Fig. 1) is characterised by progressive pathological lysosomal storage of GAGs in nearly all cell types, tissues and organs.

Oropharyngeal and tracheo-bronchial deposition of GAGs leads to severe airway obstruction due to macroglossia, supraglottic narrowing, and tracheomalacia. This obstructive anatomy and physiology leads to sleep apnoea and airway obstruction. As the disease progresses, the respiratory system is further compromised by pulmonary restriction secondary to the effects of the disease on the thoracic skeleton. Deposition of GAGs in the heart, liver and spleen leads to cardiomyopathy, cardiac valve dysplasia and hepatosplenomegaly. Bone and joint involvement results in severe skeletal deformities and limitations of joint mobility. In patients with CNS involvement, severe learning difficulties and progressive neurological decline occur. The clinical manifestations of MPS II generally lead to death in the first or second decade of life, although in the more attenuated form of MPS II, death may occur in early adulthood, and some patients have survived into their fifth and sixth decades of life.

Until recently, there has been no effective therapy for MPS II. Care has been palliative, focusing on management of the multiple clinical symptoms. Haematopoietic stem cell therapy (HSCT) has been attempted in some patients [36], but the long-term results have been unsatisfactory. The recent introduction of enzyme replacement therapy (ERT) with recombinant human I2S (idursulfase), however, has raised the possibility that the burden of GAG storage can be reduced and that the progressive tissue and organ damage associated with MPS II can be slowed or even prevented. The availability of ERT thus requires a greater awareness and understanding of the disease amongst a range of medical specialists and primary care physicians, so that early diagnosis can be made and treatment started before organ damage becomes irreversible.

This article gives an overview of the clinical manifestations, diagnosis and symptomatic management of patients with MPS II and provides, for the first time, recommendations for the use of ERT.

\section{Incidence and inheritance}

Data from The Netherlands and Germany indicate that the incidence of MPS II is 1.3 per 100,000 male live births [1,23]. Two-thirds of patients present with CNS involvement, representing the more severe end of the disease phenotype. There have been very few reports of recurrent or common mutations within the gene encoding I2S. As a consequence, genotype-phenotype correlations have been difficult to establish, with the exception of those patients who present with large deletions, which are most often associated with more severe disease [38].

As MPS II is an X-linked recessive condition, it would not be expected to affect females. Despite this, a few girls have been reported with MPS II [35]. Affected females generally have low levels of I2S activity and an attenuated clinical phenotype, although the somatic abnormalities can be severe in some individuals. In affected heterozygous females, skewed inactivation of the X-chromosome prevents expression of the normal allele [35].

\section{Molecular basis of MPS II}

MPS II is the only known X-linked MPS disorder. The human gene encoding I2S has been mapped to Xq28. It
Fig. 1 Appearance of a child with mucopolysaccharidosis type II (Hunter syndrome) at (a) 6 years of age and (b) 12 years of age, illustrating the 'typical' clinical phenotype at the more severe end of the disease spectrum. The manifestations of the syndrome and the rate of progression, however, may vary widely among individual patients

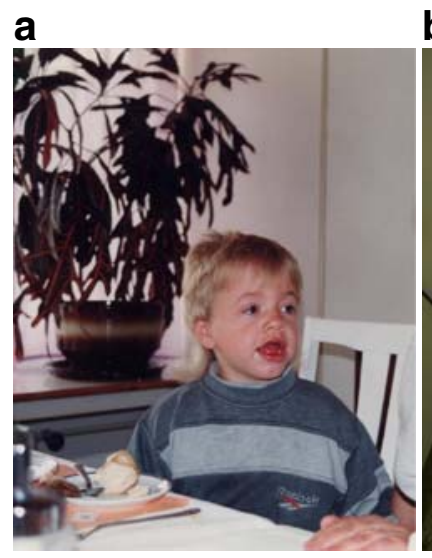

b

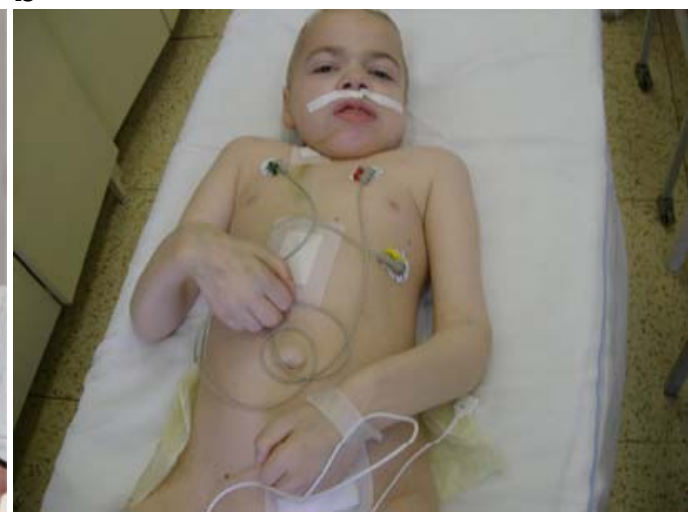


contains nine exons spread over $24 \mathrm{~kb}$. Individuals with major deletions or rearrangements in the gene usually have severe MPS II. An I2S-like pseudogene, comprising copies of exons 2 and 3 and intron 7, is located about $20 \mathrm{~kb}$ from the active gene [34]. A recurring rearrangement is due to recombination between the intron region of the gene and a homologous region near exon 3 of the pseudogene, with inversion of the intervening DNA [3]. Very large deletions of the I2S locus may extend to adjoining genes, as the neighbouring DNA is gene rich. A contiguous gene syndrome involving fragile $\mathrm{X}$ mental retardation (FMRI and FMR2) genes could possibly explain the unusual phenotypes seen in some severely affected patients [33]. Over 150 different mutations, resulting in a spectrum of disease phenotypes, have been described.

\section{General disease manifestations and diagnosis}

Treatment of possible disease complications can greatly improve quality of life. Early diagnosis is therefore essential, particularly with the recent introduction of ERT. Table 1 shows the common presenting features of patients with MPS II, together with the range of specialists who are likely to be involved in diagnosis and care.

Table 1 Presenting features of patients with mucopolysaccharidosis type II (Hunter syndrome) and the specialists likely to be involved in diagnosis and treatment

\begin{tabular}{ll}
\hline Presenting feature & Specialist \\
\hline Recurrent upper respiratory tract & Paediatrician \\
infections, recurrent otitis media, & Paediatric \\
developmental delay, hepatosplenomegaly, & neurologist \\
joint restriction, coarse facies & Otolaryngologist \\
Recurrent ear infections, abdominal & Primary care \\
distension, stiff joints & physician \\
Umbilical and inguinal hernias & Surgeon \\
with recurrence & \\
Hip dysplasia, arthropathy & Orthopaedic \\
& specialist \\
Upper airway obstruction, sleep apnoea, & Otolaryngologist \\
recurrent ear infections requiring tube & \\
placement & \\
Papilloedema in the absence of raised & Ophthalmologist \\
intracranial pressure & \\
Valvular thickening on echocardiography & Cardiologist \\
Joint pain and restriction & Rheumatologist \\
Papular pearly rash across the scapulae & Dermatologist \\
Restrictive joint range of motion & Physiotherapist \\
Carpal tunnel syndrome & Hand surgeon \\
Cervical myelopathy & Neurosurgeon \\
\hline
\end{tabular}

\section{Clinical spectrum of MPS II}

MPS II is a variable, progressive, multisystem disorder. In most patients, symptoms are severe and death occurs at an early age. In other patients the disease has a more chronic and protracted course. The age of presentation of MPS II is also variable, as are the presenting signs and disease complications. Figure 2 shows the age at onset of the main signs and symptoms of the disease in a cohort of 82 patients enrolled in HOS, the Hunter Outcome Survey. This is a multinational long-term outcomes survey to investigate the natural history of MPS II and the safety and efficacy of ERT with idursulfase [8].

The traditional classification of patients into 'mild' or 'severe' subtypes, on the basis of length of survival and the presence or absence of CNS disease, is a gross simplification. The disorder should rather be regarded as a continuum between two extremes (severe and attenuated). It is important to note that individuals who are diagnosed with an attenuated form of the disease may still have symptoms and complications that lead to significant morbidity and disability, and may present with mild to moderate learning difficulties. Although the clinical course for the more severely affected patients is relatively predictable, there is considerable variability in the clinical phenotype and progression of the more attenuated form of the disease.

Individuals with attenuated MPS II are most often diagnosed between the ages of 4 and 8 years. For the majority of these affected patients, the clinical course is very similar to the intermediate form of MPS I (MPS IH/S, Hurler-Scheie disease). Survival to adulthood is common, but death often occurs between the ages of 20 and 30 years from cardiac or respiratory disease (Fig. 3). A few patients are less severely affected. In these, life expectancy can be near normal, and such affected males may have children [9].

Patients with the more severe form of MPS II exhibit a chronic and progressive disease involving multiple organs and tissues. They appear normal at birth, although they tend to be heavy, some have inguinal or umbilical hernias and there is an increased incidence of Mongolian blue spots [25]. The age at diagnosis is usually between 18 and 36 months, compared with 9 months for severe MPS I [6]. Death from a combination of neurological deterioration and cardiorespiratory failure usually occurs in the mid-teenage years.

\section{Physical appearance}

The typical patient with attenuated MPS II is short with some change of facial features. Significant arthropathy and connective tissue involvement lead to joint contractures. A combination of hepatomegaly and lax abdominal muscles leads to abdominal prominence. 
Fig. 2 Reported age at onset and prevalence of clinical features in 82 patients with mucopolysaccharidosis type II (Hunter syndrome) enrolled in HOS, the Hunter Outcome Survey

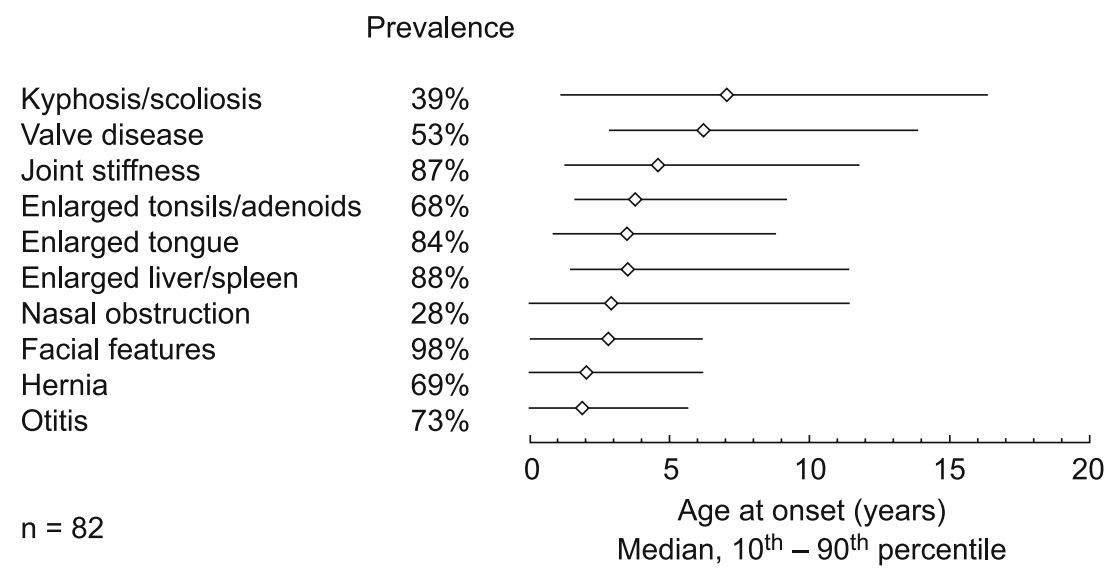

outcomes, however, are highly variable. Significant psychosocial problems occur in affected teenagers and young adults [40]. Even in patients with attenuated disease, cranial magnetic resonance imaging (MRI) scans are often grossly abnormal, with extensive white matter changes as well as dilated perivascular spaces, despite apparently normal intellectual skills [27].

Patients with more severe MPS II also appear normal at birth, and early developmental milestones may be normal. Some patients fail hearing screening tests in the first year, and speech delay is not unusual in more severely affected patients. By 18-24 months, developmental delay is usually apparent. Most patients make very slow progress after this stage, with a developmental plateau beginning between 3 and 5 years of age. Unlike children with severe MPS I, who are usually placid, more severely affected children with MPS II can be hyperactive and aggressive. By the time of death in their second decade, most patients with CNS involvement are severely mentally handicapped and dependant on care providers for all their needs.

\section{Biochemical diagnosis}

Assessing urinary GAGs (heparan and dermatan sulphates) is the usual first screening test for MPS II, and can be quantitative (measurement of total urinary uronic acid) or qualitative (GAG electrophoresis). Although neither test can offer a definitive diagnosis, abnormal measurements indicate the likely presence of an MPS disorder. The sensitivity of these tests, however, is not perfect, particularly when measurements are made on samples of dilute urine. Definitive diagnosis is established by enzyme assay in leukocytes, fibroblasts or plasma, using substrates specific for I2S. Another sulphatase should be measured in conjunction, in order to exclude multiple sulphatase deficiency. This is a much rarer disorder than MPS II and is generally associated with a very poor prognosis. It should be noted that the amount of enzyme activity measured in vitro from cellular extracts 
does not indicate where an individual falls within the MPS II spectrum of disease severity.

Prenatal diagnosis

Prenatal testing is available for foetuses at risk of MPS II. This is generally carried out by enzyme assay of $\mathrm{I} 2 \mathrm{~S}$ in uncultured chorionic villi, allowing early testing and rapid diagnosis of affected foetuses. Very low activities have been measured in some pregnancies with a (heterozygous) female foetus, emphasising the need to combine an enzyme assay with foetal sex determination [7]. Molecular-genetic prenatal testing can be performed if the mutation is known in the family.

\section{Carrier testing}

Previous methods of carrier detection based on an I2S assay in either plasma or hair roots are now known to be unreliable, as there is considerable overlap between the normal and heterozygous ranges. The only definitive test for determining carrier status is based on DNA analysis. In a small number of families, however, the mutation remains elusive, despite full sequencing of the I2S locus.

\section{Symptomatic treatment}

Even with the introduction of ERT, patients with MPS II still require supportive symptomatic treatment from a wide range of specialists. A comprehensive initial assessment of each patient at diagnosis should therefore be undertaken, and should be followed by regular reviews. Supportive management and the anticipation of possible complications can greatly improve the quality of life of affected individuals and their families. Family members should be offered genetic counselling, and contact with other affected families, patients and support groups can be helpful.

\section{Skeletal abnormalities}

Orthopaedic complications, caused by a combination of direct bone involvement and severe arthropathy, can lead to significant disability. The destructive arthropathy, which especially affects the hip joints, is a feature of the skeletal disease in some patients and may be due to secondary events occurring within chondrocytes and/or osteoblasts as a result of storage.

Progressive arthropathy may affect all joints and leads to severe restriction of motion. The hip joints appear to be particularly vulnerable and severe erosive hip dysplasia can be especially disabling. Poor hand function, due to the characteristic claw-hand deformity, carpal tunnel syndrome and interphalangeal joint stiffness, is also common.
Abnormal joint function is largely a result of both metaphyseal deformities and thickened joint capsules. Secondary erosive joint disease is particularly disabling and is extremely difficult to manage medically and/or surgically. The deformed acetabulum and pelvis makes prosthetic surgery a challenge, and many patients become wheelchair-bound because of hip pain. The role of physical therapy in MPS II is not well studied, but range-of-motion exercises appear to offer some benefit in preserving joint function and should be started at an early age. If significant restriction of joint movement has already occurred, rangeof-motion exercises may slow further progression.

\section{Cardiovascular system}

Cardiac abnormalities detected by echocardiography are common in patients with MPS II. Valvular involvement, with thickening and stiffening of the valve leaflets, commonly leads to mitral and aortic regurgitation and/or stenosis [24]. Cardiomyopathy is much less common but may be associated with an increased risk of cardiac arrhythmia [14]. Valve replacement surgery may be necessary, and annual cardiac evaluation with echocardiography is essential. Bacterial endocarditis prophylaxis should be used where appropriate. The prevalence and age at onset of the main cardiovascular signs and symptoms as reported in HOS are shown in Table 2.

\section{Respiratory disease and upper airway manifestations}

Chronic recurrent rhinitis and persistent copious nasal discharge without obvious infection are common. Enlargement of the tonsils and adenoids, a narrowed trachea, tracheomalacia, thickened vocal cords, redundant tissue in the upper airway, and an enlarged tongue can contribute to upper airway complications [4, 26, 39]. The upper airway involvement leads to noisy breathing, particularly at night, and is probably a major component of obstructive sleep apnoea, which is a common complication in the later stages

Table 2 Prevalence and reported age at onset (median and 10th-90th percentiles) of the main cardiovascular manifestations of mucopolysaccharidosis type II (Hunter syndrome) in a cohort of 82 patients in HOS, the Hunter Outcome Survey

\begin{tabular}{llll}
\hline Cardiac manifestation & $n$ & $\begin{array}{l}\text { Prevalence } \\
(\%)\end{array}$ & $\begin{array}{l}\text { Age at onset } \\
\text { (years) }\end{array}$ \\
\hline Valvular disease & 34 & 53 & $6.2(2.9-13.8)$ \\
Murmur & 32 & 52 & $6.4(3.7-12.3)$ \\
Cardiomyopathy & 4 & 9 & $7.6(5.2-27.3)$ \\
$\begin{array}{l}\text { Any cardiovascular sign/ } \\
\text { symptom }\end{array}$ & 49 & 72 & $6.0(2.9-13.7)$ \\
\hline
\end{tabular}


of the disease [16]. Because of the airway disease, there is a high risk associated with anaesthesia in these patients [17].

In patients with attenuated MPS II, rhinorrhoea tends to improve with age, but upper airway obstruction and sleep apnoea become more troublesome with increasing age. A progressive restrictive respiratory defect also becomes apparent with increasing age, mainly due to progressive changes in the thoracic skeleton.

Sleep studies should form part of the regular assessment schedule, and significant episodes of hypoxia should be managed by continuous or bilevel positive airway pressure devices. Severely affected patients often find such treatment difficult to tolerate. In these patients, supplemental oxygen alone may be an acceptable alternative, but should be used with caution in patients with documented hypercapnia.

Tonsillectomy and adenoidectomy are frequently performed to correct Eustachian tube dysfunction and to decrease airway obstruction. Severely affected patients also tend to have frequent ear infections and constant rhinorrhoea. Early placement of ventilating tubes is recommended in severely affected individuals.

\section{Gastrointestinal system}

Protuberance of the abdomen and hernias caused by progressive hepatosplenomegaly are common. Although organ size can become massive, storage of GAGs in the liver and spleen does not lead to either liver or splenic dysfunction. Patients are prone to periodic bouts of watery diarrhoea, which occur without apparent cause and are not associated with malabsorption. Rectal biopsies in affected patients have demonstrated storage within gut neural cells, and an autonomic cause for episodes of diarrhoea has been postulated [10]. With age, loss of muscle strength and physical inactivity lead to constipation.

Abdominal hernias should be repaired surgically, though recurrence can occur. Diarrhoea can be controlled by diet and the use of antimotility drugs.

\section{Central nervous system}

Communicating high pressure hydrocephalus, which is common in MPS I, is rare in MPS II. Other CNS complications, such as seizures, are more common. They are usually tonic-clonic in nature and respond to standard anticonvulsant treatment.

Progressive compression of the spinal cord with resulting cervical myelopathy due to thickening of the dura (hypertrophic pachymeningitis cervicalis) and hyperplasia of the transverse ligament is common [21]. In addition, MRI scans of the craniocervical junction will often show deposition of GAG around the tip of the odontoid process. Most patients have a well-formed odontoid process and atlanto-axial subluxation is usually not a feature of MPS II. Cervical myelopathy may initially present as reduced activity, exercise intolerance or difficulty in rising from a sitting position. If it remains untreated, irreversible cord damage can occur.

Hypertrophic pachymeningitis cervicalis and cervical compression secondary to hyperplasia of the transverse ligaments should be quickly and aggressively treated in patients with attenuated disease. Early and careful cervical decompression performed by an experienced team may prevent severe and devastating consequences.

\section{Peripheral nervous system}

Carpal tunnel syndrome is common in patients with attenuated forms of MPS II and should be promptly investigated and treated. Nerve conduction studies should be conducted to monitor patients, as the typical symptoms of compression (pain, tingling or numbness) do not occur [13]. Surgical decompression of the median nerve at an early stage of involvement results in either partial or complete improvement in most patients.

Visual problems

Although corneal opacity has been reported [31], it is not generally a feature of MPS II and helps to distinguish the disorder clinically from severe MPS I and MPS VI. In addition glaucoma is rarely present, even in severely affected patients. Retinal degeneration resulting in decreased peripheral vision and poor dark adaptation is common, but often difficult to investigate fully in a severely affected patient. Disc oedema, uveal effusions and epiretinal membranes have all been reported as part of the variable ocular pathology [2, 20, 37].

Electroretinography confirms retinal degeneration in many patients, but a disturbance of vision apart from nyctalopia ('night blindness') is rare. Chronic papilloedema without evidence of raised intracranial pressure is common and may be due to deposition of GAGs within the sclera causing pressure on the optic nerve at the interscleral level [2].

Regular, annual, ophthalmological assessment is required and should include a measure of intraocular pressure. Spectacles should be prescribed as appropriate.

\section{Hearing}

Hearing loss is common in patients with severe MPS II and is correlated with the severity of somatic disease. Manifestations leading to hearing loss include frequent middle ear disease secondary to Eustachian tube dysfunction, dysostosis of the ossicles of the middle ear, scarring of the tympanic membrane, and damage to the eighth nerve. 
Audiological abnormalities usually consist of conductive deafness early in the course of the disease but as the child ages a sensorineural element appears and most patients have combined deafness once the disease is fully established [29]. Moderate to severe hearing loss develops in most adults with attenuated MPS II. In most patients there is a mixture of both conductive and sensorineural deafness [22]. Appropriate regular audiology assessment and provision of the correct auditory aids are required.

\section{Education and behaviour}

Given the intellectual involvement in the more severely affected patients, it is important that infants with MPS II are provided with a stimulating environment to encourage as much learning as possible during the early stages, as some skills may be retained during the later period of general deterioration. For patients with more attenuated forms of the disease, deafness and physical limitations may impact on education. Educational assessments of special needs should be undertaken to ensure that an appropriate educational environment is provided. This may be in a mainstream school with additional help or within a special school system.

Many patients with severe MPS II exhibit hyperactivity and aggression. Psychological assessment, behaviour management and the use of medication should be considered in these patients. The hyperactivity generally responds poorly to methylphenidate, and over-sedation is a risk with other forms of medication.

\section{Anaesthetic complications}

All patients with MPS II present major anaesthetic risks, and death can result if appropriate precautions are not taken [12]. Patients should only undergo general anaesthesia in centres staffed with anaesthesiologists experienced in these disorders. The most important complications relate to the following.

- Dysostosis multiplex leading to rigidity of the neck and spine. Although instability of the spine is rare, significant cervical compression may be present in patients with attenuated disease. This can result in sudden neurological deterioration if excessive neck manipulation is performed during attempts to intubate the patient.

- Induction may be difficult because of an inability to maintain an adequate airway.

- Intubation may require smaller-than-anticipated endotracheal tubes and a narrow trachea and thickened vocal cords will impede view. It is recommended that a paediatric pulmonologist or ear, nose and throat specialist should be present during intubation. Fibreoptic laryngotracheoscopy is usually essential.
- Extubation can also be hazardous for these patients, and there is an increased incidence of post-obstructive pulmonary oedema.

- Recovery from anaesthesia may be slow, and postoperative airway obstruction is always a risk.

\section{Enzyme replacement therapy}

Recombinant I2S (idursulfase; Elaprase, Shire Human Genetic Therapies, Cambridge, MA, USA) has recently been licensed for treatment of patients with MPS II in the United States, European Union and Switzerland. Idursulfase is produced in a continuous human cell line and is a purified form of the natural lysosomal enzyme I2S. Mannose-6-phosphate (M6P) residues on the oligosaccharide chains of the glycoprotein enzyme allow specific binding of idursulfatase to M6P receptors on the cell surface, leading to cellular internalisation and targeting of the enzyme to lysosomes, and subsequent catabolism of accumulated GAGs.

\section{Phase I/II trial}

Twelve patients were enrolled in a randomized, doubleblind, placebo-controlled trial of idursulfase for 24 weeks, followed by an open-label extension study.

Urinary GAGs were reduced within 2 weeks of initiating idursulfase treatment and remained low for the 48 weeks of the study $(P<0.0001)$. Both liver and spleen volumes were decreased at 24 weeks $(P<0.01)$ and 48 weeks $(P<0.001)$. The distance that patients could walk in 6 min $(6$-min walk test) increased by an average of $48 \mathrm{~m}$ after 48 weeks $(P=$ 0.013). Six patients developed $\operatorname{IgG}$ antibodies that did not appear to influence the clinical response to idursulfase [18].

\section{Phase II/III trial}

A multinational, randomized, double-blind, placebo-controlled trial was performed to evaluate the safety and efficacy of idursulfase, $0.5 \mathrm{mg} / \mathrm{kg}$ administered weekly, compared with placebo. Additionally, the trial evaluated idursulfase, $0.5 \mathrm{mg} / \mathrm{kg}$ every other week, compared with placebo. Ninety-six patients were randomized to one of three groups with each patient receiving a total of 52 infusions of either idursulfase, idursulfase alternating weekly with placebo, or placebo. The primary efficacy endpoint of the trial was a composite of two clinical measures - forced vital capacity and the 6-min walk test.

Patients receiving the weekly dosing regimen of idursulfase showed a statistically significant improvement in the primary efficacy endpoint $(P<0.005)$ compared with 
placebo. Patients receiving the alternate-week dosing regimen of idursulfase also showed a statistically significant improvement $(P<0.05)$ compared with placebo [19].

Treatment with idursulfase was generally well tolerated. The most common adverse events observed were associated with the clinical manifestations of MPS II. Of the adverse events considered possibly related to idursulfase, infusionrelated reactions were the most common and were generally mild. There were two patient deaths during the study, both of which were considered unrelated to treatment with idursulfase. IgG and IgM antibodies were observed in the idursulfase-treated patients at some point during the course of the study. When antibodies occurred, there was a transient increase in urinary GAGs, presumably due to a neutralising effect. This did not correlate with any of the clinical variables measured (Shire HGT, data on file). No IgE antibodies were observed and no patient withdrew from the trial due to an adverse event considered related to idursulfase [19].

\section{Current treatment with idursulfase}

Idursulfase is given by weekly intravenous infusion over $3 \mathrm{~h}$ at a dose of $0.5 \mathrm{mg} / \mathrm{kg}$ diluted in an appropriate volume of saline (according to weight). Patients may receive premedication with antipyretics and/or antihistamines at the discretion of the prescribing physician. Patients who have experienced infusion-related reactions should be premedicated for subsequent infusions. Consideration should be given to the possibility of sodium overload in small infants, and, if necessary, the total volume of the infusion can be decreased to $50 \mathrm{ml}$. Although the treatment is generally safe and infusion-related reactions are no more frequent than with other protein-based therapies, anaphylactoid reactions have been reported.

\section{Early response to ERT}

The response to ERT appears to depend on the severity of the individual's condition and the age at which the treatment begins. In our experience, the first sign of efficacy in most young (prepubertal) patients is usually an enhanced feeling of wellbeing and greater energy, manifesting as an increased ability to take part in normal daily activities. By 2 months, most patients have urinary GAG levels approaching the normal range and there is usually evidence of a reduction in size of the liver and spleen. After a further month of therapy there is often an improvement in soft-tissues joint contractures and the beginning of a growth spurt. By 6 months of treatment, most patients have improved the distance that they can achieve in the 6-min walk test and most show stabilisation (if not improvement) in pulmonary function tests. Most of the improvement occurs in the first $12-18$ months of treatment. After this period of time, gains are very slow and the condition of most patients will generally have stabilised, although physicians still need to be vigilant and look actively for possible disease-related complications.

\section{ERT for particular patient groups}

\section{Treating very young patients}

Experience of treating children under the age of 5 years with idursulfase is limited, as the clinical trials enrolled patients above this age so that the patients would be able to comply with and be able to cooperate with repeated pulmonary function and endurance testing. The following is therefore based on our personal clinical experience. Treating patients at a very young age leads to practical problems with the infusions. These may be resolved with indwelling vascular access devices. Outcomes are likely to be better in patients treated from a very young age, but there are currently no recommendations on how to monitor the response to treatment, especially in patients either too young to cooperate with the tests used in the clinical trials (pulmonary function tests and 6-min walk test) or in patients who are not yet showing symptoms of the disease. This situation would be improved by identifying a suitable biomarker that would reflect the disease burden and that would respond promptly to therapy.

We believe that these challenges should not prevent the introduction of treatment in patients under the age of 5 years after discussion with parents. Careful clinical follow-up, however, will be necessary in these patients, accompanied by regular (annual) developmental assessments. As of October 2006, there were 12 patients below 5 years of age in HOS.

Treating patients with severe CNS involvement

Idursulfase is not expected to cross the blood-brain barrier and therefore would not be expected to lead to any improvement in CNS dysfunction in patients with severe MPS II. In most patients there is likely to be some initial benefit in terms of enhanced respiratory function due to airway improvement and reduction in size of the liver and spleen. In addition, joint mobility may improve as a result of ERT on peri-articular soft tissue. The burden of weekly intravenous therapy may be significant in some patients with very severe CNS disease. The authors believe that patients with severe CNS involvement may be offered the possibility of treatment for a 'trial' period of 12-18 months, after which time a decision should be made as to whether to continue. Decisions on whether to start and continue treatment should be made only after detailed discussion with the parents. 
Home therapy

More than $90 \%$ of patients treated with idursulfase have had no infusion-related reactions and, in those who do, the reactions are mostly minor and respond promptly to reducing the rate of infusion and using antipyretics and antihistamines for future treatments. Under these circumstances, it would appear that idursulfase is a therapy that could be administered safely in the patient's home after a minimum of 12 infusions in hospital.

Depending on the labelling and clinical practices in particular countries, a logical approach would appear to be to consider home therapy for those patients with minimal or no obstructive airway disease (as judged by sleep study and pulmonary function tests). It should be stressed, however, that ERT during respiratory infections or other intercurrent illnesses are contraindicated. Treatment should be postponed under such circumstances, regardless of whether treatment is given in the hospital or home setting.

\section{Management of infusion reactions}

Infusion-related reactions appear to be of two types: those occurring during the infusion and 'late' reactions occurring $12 \mathrm{~h}$ or more after the infusion.

The classic reactions occurring during the infusion, with fever, chills and urticaria, respond to temporarily stopping the infusion, administering paracetamol (acetominophen) and antihistamines, and restarting the infusion after at least $30 \mathrm{~min}$ but at a slower rate. Before subsequent infusions, patients should be premedicated with acetominophen and antihistamines $1 \mathrm{~h}$ before the infusion. If the reactions continue despite this premedication, consideration should be given to pretreatment with corticosteroids; for example, prednisolone, $1 \mathrm{mg} / \mathrm{kg}, 12 \mathrm{~h}$ and $1 \mathrm{~h}$ before infusion.

Late reactions typically consist of a sunburn-type rash and mild wheezing. The rash can be managed as above, but the wheezing requires bronchodilator treatment and, possibly, oxygen supplementation. All patients who have significant infusion-associated reactions should have specific immune testing. Reducing the rate of infusion is mandatory in these patients.

To assess the efficacy of ERT in individual patients and to ensure the appropriate management of possible infusion-related reactions, it is recommended that the treatment of patients receiving ERT is overseen by experienced physicians in centres with expertise in treating lysosomal storage diseases.

\section{Haematopoietic stem cell therapy}

The potentially beneficial effect of HSCT on lysosomal storage diseases is thought to be due to the replacement of deficient macrophages with marrow-derived donor macrophages (Kupffer cells - pulmonary, splenic, nodal, tonsillar and peritoneal macrophages - and microglial cells) which constitute an ongoing source of enzyme capable of gaining access to various storage sites. HSCT has been successful in modifying the course of the disease in patients with severe MPS I and MPS VI. In a single small study of HSCT in MPS II, however, the results of treatment were not positive, with nine of ten patients continuing to exhibit progressive neurodegeneration [36].

\section{The future}

Whilst ERT is likely to benefit many patients with MPS II, the problems associated with severe CNS involvement are unlikely to be solved by intravenous ERT. Other methods of treatment, including alternative routes of enzyme administration, will therefore need to be studied. Direct administration of enzyme into the cerebrospinal fluid, either into the ventricle or lumbar space, has not prevented progressive neurological deterioration in another lysosomal storage disorder, type II Gaucher disease [28]. This approach has not been attempted in MPS II, and formal studies are required, perhaps with the addition of immunosuppression to prevent antibody formation. Currently, there are no suitable methods for infusion directly into the brain, and repeated intracerebral injections would not be practical. It may be that to treat CNS disease more effectively, peripheral ERT may have to be combined with other approaches, such as cell-based therapies, perhaps involving gene enhancement or replacement.

Gene therapy is the logical approach for treating disorders of the CNS, and animal work on other MPS disorders is beginning to show promise $[5,30]$. Choice of vector, the use of immunosuppression and the route of administration are all issues that need addressing before the first human clinical trials of gene therapy involving MPS disorders are performed.

Use of nanoparticles containing engineered myoblasts expressing I2S has been reported. Scaling-up studies, however, are required to evaluate the feasibility of such devices [11].

\section{Conclusion}

MPS II (Hunter syndrome) is a severe progressive multisystemic disorder that has the potential to cause disease in most body systems and is usually fatal in the second or third decade of life. Ideally, management should be centralised in major medical centres with access to all medical specialties. 
Management is multidisciplinary and a holistic approach to the patient is required, especially for those who have severe neurological involvement. ERT is an important new therapy that has the potential to help many patients, providing that it is started early in the course of the disease. CNS disease remains a major challenge and an innovative approach to treatment will be needed if this is to be addressed fully.

Open Access This article is distributed under the terms of the Creative Commons Attribution Noncommercial License which permits any noncommercial use, distribution, and reproduction in any medium, provided the original author(s) and source are credited.

\section{References}

1. Baehner F, Schmiedeskamp C, Krummenauer F, Miebach E, Bajbouj M, Whybra C, Kohlschutter A, Kampmann C, Beck M (2005) Cumulative incidence rates of the mucopolysaccharidoses in Germany. J Inherit Metab Dis 28:1011-1017

2. Beck M, Cole G (1984) Disc oedema in association with Hunter's syndrome: ocular histopathological findings. $\mathrm{Br} \mathrm{J}$ Ophthalmol 68:590-594

3. Bondeson ML, Dahl N, Malmgren H, Kleijer WJ, Tonnesen T, Carlberg BM, Pettersson U (1995) Inversion of the IDS gene resulting from recombination with IDS-related sequences is a common cause of the Hunter syndrome. Hum Mol Genet 4:615-621

4. Brama I, Gay I, Feinmesser R, Springer C (1986) Upper airway obstruction in Hunter syndrome. Int J Pediatr Otorhinolaryngol 11:229-235

5. Casal M, Haskins M (2006) Large animal models and gene therapy. Eur J Hum Genet 14:266-272

6. Cleary MA, Wraith JE (1995) The presenting features of mucopolysaccharidosis type IH (Hurler syndrome). Acta Paediatr 84:337-339

7. Cooper A, Thornley M, Wraith JE (1991) First-trimester diagnosis of Hunter syndrome: very low iduronate sulphatase activity in chorionic villi from a heterozygous female fetus. Prenat Diagn 11:731-735

8. Del Toro-Riera M (2007) Follow-up of patients with Hunter syndrome: the Hunter Outcome Survey (HOS) registry (in Spanish). Rev Neurol 44(Suppl 1):S13-17

9. DiFerrante N, Nichols BL (1972) A case of the Hunter syndrome with progeny. Johns Hopkins Med J 130:325-328

10. Elsner B (1970) Ultrastructure of the rectal wall in Hunter's syndrome. Gastroenterology 58:856-862

11. Friso A, Tomanin R, Alba S, Gasparotto N, Puicher EP, Fusco M, Hortelano G, Muenzer J, Marin O, Zacchello F, Scarpa M (2005) Reduction of GAG storage in MPS II mouse model following implantation of encapsulated recombinant myoblasts. J Gene Med 7:1482-1491

12. Gaitini L, Fradis M, Vaida S, Collins G, Croitoru M, Somri M, Borochovitz Z, Golz A (1998) Failure to control the airway in a patient with Hunter's syndrome. J Laryngol Otol 112:380-382

13. Haddad FS, Jones DH, Vellodi A, Kane N, Pitt MC (1997) Carpal tunnel syndrome in the mucopolysaccharidoses and mucolipidoses. J Bone Joint Surg Br 79:576-582

14. Hishitani T, Wakita S, Isoda T, Katori T, Ishizawa A, Okada R (2000) Sudden death in Hunter syndrome caused by complete atrioventricular block. J Pediatr 136:268-269

15. Hunter C (1917) A rare disease in two brothers. Proc R Soc Med 10:104-106
16. Leighton SE, Papsin B, Vellodi A, Dinwiddie R, Lane R (2001) Disordered breathing during sleep in patients with mucopolysaccharidoses. Int J Pediatr Otorhinolaryngol 58:127-138

17. Moores C, Rogers JG, McKenzie IM, Brown TC (1996) Anaesthesia for children with mucopolysaccharidoses. Anaesth Intensive Care 24:459-463

18. Muenzer J, Gucsavas-Calikoglu M, McCandless SE, Schuetz TJ, Kimura A (2007) A phase I/II clinical trial of enzyme replacement therapy in mucopolysaccharidosis II (Hunter syndrome). Mol Genet Metab 90:329-337

19. Muenzer J, Wraith JE, Beck M, Giugliani R, Harmatz P, Eng CM, Vellodi A, Martin R, Ramaswami U, Gucsavas-Calikoglu M, Vijayaraghavan S, Wendt S, Puga AC, Ulbrich B, Shinawi M, Cleary M, Piper D, Conway AM, Kimura A (2006) A phase II/III clinical study of enzyme replacement therapy with idursulfase in mucopolysaccharidosis II (Hunter syndrome). Genet Med 8:465473

20. Narita AS, Russell-Eggitt I (1996) Bilateral epiretinal membranes: a new finding in Hunter syndrome. Ophthalmic Genet 17:75-78

21. Parsons VJ, Hughes DG, Wraith JE (1996) Magnetic resonance imaging of the brain, neck and cervical spine in mild Hunter's syndrome (mucopolysaccharidoses type II). Clin Radiol 51:719-723

22. Peck JE (1984) Hearing loss in Hunter's syndrome - mucopolysaccharidosis II. Ear Hear 5:243-246

23. Poorthuis BJ, Wevers RA, Kleijer WJ, Groener JE, de Jong JG, van Weely S, Niezen-Koning KE, van Diggelen OP (1999) The frequency of lysosomal storage diseases in The Netherlands. Hum Genet 105:151-156

24. Rigante D, Segni G (2002) Cardiac structural involvement in mucopolysaccharidoses. Cardiology 98:18-20

25. Sapadin AN, Friedman IS (1998) Extensive Mongolian spots associated with Hunter syndrome. J Am Acad Dermatol 39:10131015

26. Sasaki CT, Ruiz R, Gaito R, Jr., Kirchner JA, Seshi B (1987) Hunter's syndrome: a study in airway obstruction. Laryngoscope 97:280-285

27. Shinomiya N, Nagayama T, Fujioka Y, Aoki T (1996) MRI in the mild type of mucopolysaccharidosis II (Hunter's syndrome). Neuroradiology 38:483-485

28. Sidransky E (1997) New perspectives in type 2 Gaucher disease. Adv Pediatr 44:73-107

29. Simmons MA, Bruce IA, Penney S, Wraith E, Rothera MP (2005) Otorhinolaryngological manifestations of the mucopolysaccharidoses. Int J Pediatr Otorhinolaryngol 69:589-595

30. Sleeper MM, Fornasari B, Ellinwood NM, Weil MA, Melniczek J, O'Malley TM, Sammarco CD, Xu L, Ponder KP, Haskins ME (2004) Gene therapy ameliorates cardiovascular disease in dogs with mucopolysaccharidosis VII. Circulation 110:815-820

31. Spranger J, Cantz M (1978) Mucolipidosis I, the cherry red-spotmyoclonus syndrome and neuraminidase deficiency. Birth Defects Orig Artic Ser 14:105-112

32. Thappa DM, Singh A, Jaisankar TJ, Rao R, Ratnakar C (1998) Pebbling of the skin: a marker of Hunter's syndrome. Pediatr Dermatol 15:370-373

33. Timms KM, Bondeson ML, Ansari-Lari MA, Lagerstedt K, Muzny DM, Dugan-Rocha SP, Nelson DL, Pettersson U, Gibbs RA (1997) Molecular and phenotypic variation in patients with severe Hunter syndrome. Hum Mol Genet 6:479-486

34. Timms KM, Lu F, Shen Y, Pierson CA, Muzny DM, Gu Y, Nelson DL, Gibbs RA (1995) $130 \mathrm{~kb}$ of DNA sequence reveals two new genes and a regional duplication distal to the human iduronate-2-sulfate sulfatase locus. Genome Res 5:71-78

35. Tuschl K, Gal A, Paschke E, Kircher S, Bodamer OA (2005) Mucopolysaccharidosis type II in females: case report and review of literature. Pediatr Neurol 32:270-272 
36. Vellodi A, Young E, Cooper A, Lidchi V, Winchester B, Wraith JE (1999) Long-term follow-up following bone marrow transplantation for Hunter disease. J Inherit Metab Dis 22:638-648

37. Vine AK (1986) Uveal effusion in Hunter's syndrome. Evidence that abnormal sclera is responsible for the uveal effusion syndrome. Retina 6:57-60

38. Wraith JE, Cooper A, Thornley M, Wilson PJ, Nelson PV, Morris CP, Hopwood JJ (1991) The clinical phenotype of two patients with a complete deletion of the iduronate-2-sulphatase gene (mucopolysaccharidosis II-Hunter syndrome). Hum Genet 87:205206

39. Yoskovitch A, Tewfik TL, Brouillette RT, Schloss MD, Der Kaloustian VM (1998) Acute airway obstruction in Hunter syndrome. Int J Pediatr Otorhinolaryngol 44:273-278

40. Young ID, Harper PS (1981) Psychosocial problems in Hunter's syndrome. Child Care Health Dev 7:201-209 